\title{
Article
}

\section{Estimation and classification of popping expansion capacity in popcorn breeding programs using NIR spectroscopy}

Ferreira de Oliveira, Gustavo Hugo, Murray, Seth C., Cunha Júnior, Luis Carlos, Gomes de Lima, Kássio Michell, Medeiros-De-morais, Camilo De lelis, Henrique de Almeida Teixeira, Gustavo and Môro, Gustavo Vitti

Available at http://clok.uclan.ac.uk/30398/

Ferreira de Oliveira, Gustavo Hugo, Murray, Seth C., Cunha Júnior, Luis Carlos, Gomes de Lima, Kássio Michell, Medeiros-De-morais, Camilo De lelis ORCID: 0000-0003-2573-787X, Henrique de Almeida Teixeira, Gustavo and Môro, Gustavo Vitti (2020) Estimation and classification of popping expansion capacity in popcorn breeding programs using NIR spectroscopy. Journal of Cereal Science, 91 (102861). ISSN 0733-5210

It is advisable to refer to the publisher's version if you intend to cite from the work. http://dx.doi.org/10.1016/j.jcs.2019.102861

For more information about UCLan's research in this area go to http://www.uclan.ac.uk/researchgroups/ and search for <name of research Group>.

For information about Research generally at UCLan please go to http://www.uclan.ac.uk/research/

All outputs in CLoK are protected by Intellectual Property Rights law, including Copyright law. Copyright, IPR and Moral Rights for the works on this site are retained by the individual authors and/or other copyright owners. Terms and conditions for use of this material are defined in the policies page. 
Estimation and classification of popping expansion capacity in popcorn breeding programs

4 Gustavo Hugo Ferreira de Oliveira ${ }^{1}$, Seth C. Murray ${ }^{2}$, Luis Carlos Cunha Júnior ${ }^{3}$, Kássio Michell

5 Gomes de Lima ${ }^{4}$, Camilo de Lelis Medeiros de Morais ${ }^{5}$, Gustavo Henrique de Almeida

6 Teixeira $^{6}$, Gustavo Vitti Môro ${ }^{6}$

$8 \quad{ }^{1}$ Universidade Federal de Sergipe (UFS), Núcleo de Graduação de Agronomia. Nossa Senhora da 9 Glória/Sergipe, Brazil. Rodovia Engenheiro Jorge Neto, km 3, Silos, CEP: 49.680-000. Nossa

10 Senhora da Glória, Sergipe, Brazil

$11{ }^{2}$ Texas A\&M University, Department of Soil and Crop Science, 2474 TAMU MS, College

12 Station, 77843. College Station, Texas, USA

$13{ }^{3}$ Universidade Federal de Goiás (UFG), Escola de Agronomia (EA), Setor de Horticultura.

14 Rodovia Goiânia Nova Veneza, km 0, Campus Samambaia. Caixa Postal 131, Goiânia - GO,

15 Brazil. CEP: 74.690-900

$16{ }^{4}$ Universidade Federal do Rio Grande do Norte (UFRN), Instituto de Química, Química

17 Biológica e Quimiometria, Avenida Senador Salgado Filho, n 3000, Bairro de Lagoa Nova,

18 CEP: 59.078-970, Natal, Rio Grande do Norte, Brazil

$19{ }^{5}$ University of Central Lancashire, School of Pharmacy and Biomedical Sciences, Preston,

20 Lancashire, PR1 2HE, United Kingdom

$21{ }^{6}$ Universidade Estadual Paulista (UNESP), Faculdade de Ciências Agrárias e Veterinárias

22 (FCAV), Campus de Jaboticabal. Via de Acesso Prof. Paulo Donato Castellane s/n, CEP: 14884-

23900 - Brasil, Jaboticabal, São Paulo, Brazil 
24 *Corresponding author: gv.moro@unesp.br

\section{Abstract}

One of the most important quality traits in popcorn breeding programs is the popping expansion (PE) capacity of the kernel, which is the ratio of the volume of the popcorn to the

29 weight of the kernel. In this study, we evaluated whether near infrared spectroscopy (NIR

30 spectroscopy) could be used as a tool in popcorn breeding programs to routinely predict and/or

31 discriminate popcorn genotypes on the basis of their PE. Three generations $\left(\mathrm{F}_{1}, \mathrm{~F}_{2}\right.$, and $\left.\mathrm{F}_{2: 3}\right)$

32 were developed in three planting seasons by manual cross-pollination and self-pollination. A

33 total of 376 ears from the $\mathrm{F}_{2: 3}$ generation were selected, shelled, and subjected to phenotypic

34 analysis. Genetic variability was observed in the $F_{2}$ and $F_{2: 3}$ generations, and their average PE

35 value was $31.5 \pm 6.7 \mathrm{~mL} \cdot \mathrm{g}^{-1}$. PE prediction models using partial least square (PLS) regression

36 were developed, and the root mean square error of calibration (RMSEC) was $6.08 \mathrm{~mL} \cdot \mathrm{g}^{-1}$, while

37 the coefficient of determination $\left(\mathrm{R}_{\mathrm{C}}{ }^{2}\right)$ was 0.26 . The model developed by principal component

38 analysis with quadratic discriminant analysis (PCA-QDA) was the best for discriminating the

39 kernels with low PE $\left(\leq 30 \mathrm{~mL} \cdot \mathrm{g}^{-1}\right)$ from those with high PE $\left(>30 \mathrm{~mL} \cdot \mathrm{g}^{-1}\right)$ with an accuracy of

$4078 \%$, sensitivity of $81.2 \%$, and specificity of $72.2 \%$. Although NIR spectroscopy appears to be a

41 promising non-destructive method for assessing the PE of intact popcorn kernels for narrow

42 breeding populations, greater variability and larger sample sizes would help improve the

43 robustness of the predictive and classificatory models.

45 Keywords: Zea mays L., selection methods, multivariate analysis, discrimination, prediction 46 


\section{Introduction}

One of the most important quality traits in popcorn breeding programs is the popping expansion (PE) capacity of the kernel, which is defined as the ratio of the volume of the popcorn

50 to the weight of the kernel (Guimarães et al., 2000). Owing to targeted breeding and selection,

51 the PE capacity of popcorn has significantly increased over the last few decades. Recent reports

52 have demonstrated that the PE values of popcorn have approximately doubled in comparison to

53 those of the older American (25 mL.g $\left.{ }^{-1}\right)$ (Galvão et al., 2015) and Brazilian popcorn varieties (15

$54 \mathrm{~mL} \cdot \mathrm{g}^{-1}$ ) (Zinsly and Machado, 1987), and the PE values of the current popcorn breeds are 55 approximately $30 \mathrm{~mL} \cdot \mathrm{g}^{-1}$ (Amaral Junior et al., 2012; Oliveira et al., 2019).

57 farmers still rely on imported seeds, especially from the United States of America (USA), where 58 the PE capacity of popcorn is superior (Sawazaki, 2011). Additionally, since popcorn is bought 59 by weight and sold by volume, the PE capacity is a vital criterion in determining the commercial 60 value of popcorn.

61 One of the most difficult processes in popcorn breeding programs is phenotyping the high 62 numbers of genotypes for assessing their PE capacity. In addition to the time required for 63 selecting the genotypes with high PE, phenotyping destroys the kernels, as it requires heating the 64 kernels in a microwave oven for rupturing the pericarp. This is a widely accepted procedure for 65 determining the PE capacity of popcorn (Galvão et al., 2000). However, this method is 66 destructive, requires large quantities of grains, and the crosses between the different genotypes in 67 popcorn breeding programs produce a small number of kernels. Altogether, these methodological 68 disadvantages challenge the progress of popcorn breeding programs towards maximizing genetic 
69 gains. A non-destructive method would allow the assessment of superior genotypes without

70 destroying the grains, and could also accelerate the breeding process.

71 Near infrared spectroscopy (NIR spectroscopy) could provide a better alternative for

72 assessing the PE capacity of popcorn, as NIR spectroscopy is a non-destructive method for

73 measuring the chemical constituents of biological materials (Pasquini et al., 2003). The PE

74 capacity is related to the presence of a glassy (Quinn et al., 2005) or translucent endosperm with

75 densely packed starch granules, which allow the kernels to expand (van der Sman and Bows,

76 2017). NIR spectroscopy has been used to predict the composition of maize kernel and has

77 enabled the rapid selection of individual seeds with desirable traits, including the presence of

78 starch, protein, oil, and phenolics (Baye et al., 2006; Meng et al., 2015). It also has been used to

79 develop calibration models for the common varieties of corn, and for calibrating the quality traits

80 of other species (Brito et al., 2013; Sinelli et al., 2010; Williams et al., 2009).

81 In order to select popcorn varieties with NIR spectroscopy on the basis of their

82 phenotypic traits, and especially for enhanced PE capacity, samples of whole grains can be

83 quickly screened, requiring no sample preparation, and the kernels can be preserved following

84 measurement for further analyses and/or propagation. However, to the best of our knowledge,

85 there are no NIR spectroscopy calibration and/or classification models that can be applied to

86 correlate the traits of popcorn kernels in breeding programs. Therefore, the aim of this study was

87 to evaluate whether NIR spectroscopy could be routinely used a tool in popcorn breeding

88 programs for discriminating popcorn genotypes on the basis of their PE capacities.

90 2. Materials and Methods

$91 \quad$ 2.1. $\quad$ Plant Materials 
A total of 183 partial $\left(\mathrm{S}_{3}\right)$ inbred lines were obtained from nine different origins

93 (commercial hybrids cultivars). The strains were separated based on the similarity of their

94 agronomic characteristics, and nine populations were formed from the seed mix of the different

95 strains in each group. Three generations $\left(\mathrm{F}_{1}, \mathrm{~F}_{2}\right.$, and $\left.\mathrm{F}_{2: 3}\right)$ were developed in three planting

96 seasons by manual cross-pollination and self-pollination.

97 The first $\left(\mathrm{F}_{1}\right)$ and second $\left(\mathrm{F}_{2}\right)$ generations were developed at the experimental farm of 98 Universidade Estadual Paulista (UNESP), Faculdade de Ciências Agrárias e Veterinárias 99 (FCAV), Campus de Jaboticabal, located in Jaboticabal, São Paulo, Brazil (latitude 21 15' 17" S, 100 longitude $48^{\circ} 19^{\prime} 20^{\prime \prime} \mathrm{W}$, and altitude of $605 \mathrm{~m}$ ) during the season of 2012/2013. The $\mathrm{F}_{1}$ 101 generation and their reciprocal $\mathrm{F}_{1}$ ' hybrids were obtained by complete diallel crosses between the 102 populations thus formed. The $F_{2}$ generation was produced by sowing some seeds from the $F_{1}$ 103 hybrids and some seeds from the $F_{1}$ ' reciprocals in the season of 2013/2014. The $F_{2}$ generation 104 was generated by allowing self-fertilization of the hybrid combinations using the SIB (Self in 105 Brothers) crossing method, following which the $F_{2}$ seeds thus generated from the 72 hybrid 106 combinations were harvested and stored in a dry chamber.

107 The third $\left(\mathrm{F}_{2: 3}\right)$ generation was developed in 2014 at the Texas A\&M University 108 Experimental Farm located in Weslaco, Texas, USA (latitude 26 9' 33" N, longitude 97 59' 15" $109 \mathrm{~W}$, and altitude of $24 \mathrm{~m}$ ). Similar to the method employed for generating the $\mathrm{F}_{2}$ plants, the $\mathrm{F}_{2: 3}$ 110 plants were produced by self-fertilizing all the $F_{2}$ plants in the plot by manual pollination. All the 111 ears were later identified, separately harvested, and dried in the shade. A total of 376 ears from 112 the $\mathrm{F}_{2: 3}$ generation were selected, hand-shelled, and all the grains were considered for analysis. A 113 total of 120 grains were randomly selected as samples from each ear for phenotyping and 114 calibration by NIR spectroscopy. 


\subsection{Acquisition of NIR spectra}

The NIR spectra of the intact popcorn kernels were obtained using a Thermo Scientific

117 Antaris II FT-NIR Analyzer (Thermo Electron Co., USA). Prior to acquisition of the NIR

118 spectra, the kernels were allow to equilibrate in the ambient humidity for two weeks in a 119 controlled laboratory environment at $\sim 25^{\circ} \mathrm{C}$ and $12-13 \%$ relative humidity. All the measurements 120 were made in a diffuse reflectance mode using a $225 \mathrm{~mL}$ rotating cup with a capacity to hold 121 approximately $175 \mathrm{~g}$ of common maize over the integrating sphere module of the spectrometer.

122 A foam support was placed in the cup to reduce its volume so as to accommodate 120 popcorn 123 kernels per sample. A set of 331 samples was run once, with 64 scans for the samples of whole 124 kernel. All the NIR spectra were computed at a resolution of $4 \mathrm{~cm}^{-1}$ across the spectral range of $1254,000-10,000 \mathrm{~cm}^{-1}(1,000$ to $2,500 \mathrm{~nm})$ at ambient temperature $\left(\sim 25^{\circ} \mathrm{C}\right)$.

\subsection{PE assessment: reference analysis}

The samples were prepared according to the method described by Hoseney et al. (1983),

129 but the time was adjusted according to the microwave model used and the number of kernels

130 used for the study. Briefly, after scanning the samples of whole kernel by NIR spectroscopy, the 131120 kernels in each sample were divided into three sub-samples of 40 kernels each. The sub132 samples were weighed using a precision balance and popped in a paper bag in a microwave, 133 using the maximum power setting of $1,350 \mathrm{w}(60 \mathrm{~Hz})$ for one minute and 30 seconds. The 134 expansion volume of the samples was determined by calculating the mean ratio of the popcorn 135 volume to the weight of each sub-sample $\left(\mathrm{mL} \cdot \mathrm{g}^{-1}\right)$. The volume of the popcorn was measured 136 using a 1,000 mL graduated cylinder, and the cylinder was inverted once for each process to 137 prevent packing. The variability in PE capacity among the samples was measured by analysis of 
138 variance (ANOVA) using PROC MIXED in SAS software, (SAS, 2002). The analysis included

139 the $\mathrm{F}_{2}$ population and $\mathrm{F}_{2: 3}$ generation as random effects in the model.

\subsection{Chemometrics}

All the spectral data was processed in a MATLAB ${ }^{\circledR}$ R2014b environment (Mathworks,

143 Natrick, USA) using the PLS Toolbox, version 7.9.3 (Eigenvector Research, Inc., Manson, 144 USA), and in-house algorithms. The data was pre-processed by the standard normal variate 145 (SNV) method, first by the Savitzky-Golay derivative (window of 7 points, $2^{\text {nd }}$ order polynomial 146 function), followed by vector normalization prior to chemometric analyses.

147 The prediction models for discriminating popcorn kernels based on the PE capacity were 148 developed using partial least squares (PLS), interval partial least squares (iPLS), and support 149 vector regression (SVR), where $70 \%$ of the samples were selected for calibration and full cross150 validation, and the remaining $30 \%$ was set aside for external validation. The samples were split 151 into calibration and validation sets using the Kennard-Stone sample selection algorithm 152 (Kennard and Stone, 1969).

153 For classification of the kernels on the basis of the PE values, the samples were divided 154 into training (70\%), validation (15\%), and test (15\%) sets using the Kennard-Stone sample 155 selection algorithm (Kennard and Stone, 1969). The training set comprised 83 samples of class 1 156 kernels $\left(\mathrm{PE} \leq 30 \mathrm{~mL} \cdot \mathrm{g}^{-1}\right)$ and 148 samples of class 2 kernels $\left(\mathrm{PE}>30 \mathrm{~mL} \cdot \mathrm{g}^{-1}\right)$, and both the 157 validation and test sets had 18 samples of class 1 kernels and 32 samples of class 2 kernels each.

158 For classification, principal component analysis (PCA) with linear discriminant analysis 159 (PCA-LDA) and PCA with quadratic discriminant analysis (PCA-QDA) were performed. The 160 PCA-LDA and PCA-QDA algorithms are based on data reduction using PCA (Bro and Smilde, 
161 2014) followed by discrimination of the PCA scores using LDA and QDA, respectively (Dixon

162 and Brereton, 2009). The LDA $\left(L_{i k}\right)$ and QDA $\left(Q_{i k}\right)$ classification scores can be calculated by the

163 following equations described by Costa et al., (2017):

$$
\begin{aligned}
& L_{i k}=\left(\mathbf{x}_{i}-\overline{\mathbf{x}}_{k}\right)^{\mathrm{T}} \sum_{\text {pooled }}^{-1}\left(\mathbf{x}_{i}-\overline{\mathbf{x}}_{k}\right)-2 \log _{e} \pi_{k} \\
& Q_{i k}=\left(\mathbf{x}_{i}-\overline{\mathbf{x}}_{k}\right)^{\mathrm{T}} \sum_{k}^{-1}\left(\mathbf{x}_{i}-\overline{\mathbf{x}}_{k}\right)+\log _{e}\left|\sum_{k}\right|-2 \log _{e} \pi_{k}
\end{aligned}
$$

167 scores for $A$ components); $\bar{x}_{k}$ is the mean vector of class $k ; \Sigma_{\text {pooled }}$ is the pooled covariance matrix;

$168 \Sigma_{\mathrm{k}}$ is the variance-covariance matrix of class $k$; and $\pi_{k}$ is the prior probability of class $k$. The 169 values of $\Sigma_{\text {pooled }}, \Sigma_{\mathrm{k}}$, and $\pi_{k}$ are calculated by the following equations described by Costa et al., 170 (2017): matrix to calculate the discriminant function between the classes, whereas QDA uses the 178 variance-covariance matrices of each class separately (Dixon and Brereton, 2009). Therefore, 179 PCA-QDA usually achieves a better performance than PCA-LDA when analyzing complex 180 datasets where the variance structures between the classes are very different. 
184 LDA and GA-QDA algorithms, GA is initially applied to reduce the pre-processed spectral data 185 into a few number of variables based on an evolutionary process (McCall, 2005), following 186 which LDA or QDA is applied to these selected variables using Eq. 1 or 2, respectively. The 187 selected variables are of the same scale as the original spectral data and are selected according to 188 the lowest risk of misclassification $(G)$. The value of $G$ is calculated from the validation set 189 according to the following equation described by Carvalho et al. (2018):

$$
G=\frac{1}{N_{\mathrm{v}}} \sum_{n=1}^{N_{\mathrm{v}}} g_{n}
$$

Where, $N_{v}$ is the number of validation samples, and $g_{n}$ is defined as:

$$
g_{n}=\frac{r^{2}\left(x_{n}, m_{I(n)}\right)}{\min _{I(m) \neq I(n)} r^{2}\left(x_{n}, m_{I(m) s}\right.}
$$

Where, the numerator is the squared Mahalanobis distance between sample $x_{n}$ (of class index

$194 I(n))$ and the mean $m_{I(n)}$ of its true class; and the denominator represents the squared Mahalanobis 195 distance between sample $x_{n}$ and the mean $m_{I(m)}$ of the closest unselected class. The GA was 196 performed for 100 generations, with 200 chromosomes each. The cross-over and mutation 197 probabilities were set at $60 \%$ and $1 \%$, respectively. The algorithm was repeated three times and 198 the best result was chosen.

199 The classification was finally performed using soft independent modeling of class analogy 200 (SIMCA) and PLS regression with discriminant analysis (PLS-DA). SIMCA models are based 201 on PCA models in which each class corresponds to a training set (Sabin et al., 2004). The use of 202 PLS-DA maximizes the separation of pre-defined classes as it explains the variability within a 203 general dataset (Wong et al., 2013).

\subsubsection{Statistical evaluation}


The algorithms used in this study were statistically evaluated by the accuracy, sensitivity,

207 and specificity, which were calculated for each model. Sensitivity is defined as the proportion of

208 positive samples correctly classified, and specificity is defined as the proportion of negative

209 samples correctly classified. These figures of merit were calculated according to the following

210 equations described by Baia et al. (2016) and Carvalho et al. (2016):

$$
\text { Accuracy }(\%)=100-\left(\frac{1}{N} \sum_{h=1}^{H} y_{h}^{*}\right) \times 100
$$

$$
\text { Sensitivity }(\%)=\frac{\mathrm{TP}}{\mathrm{TP}+\mathrm{FN}} \times 100
$$

13

$$
\text { Specificity }(\%)=\frac{\mathrm{TN}}{\mathrm{TN}+\mathrm{FP}} \times 100
$$

214 Where, $N$ is the total number of samples; $H$ is the total number of classes; $y_{h}{ }^{*}$ is the number

215 of samples incorrectly classified in class $h$; TP is the number of true positives; TN is the number 216 of true negatives; FP is the number of false positives; and FN is the number of false negatives.

\section{Results}

\subsection{Genetic analysis}

Genetic variability was observed in the $F_{2}$ and $F_{2: 3}$ generations (Table 1). The coefficient

221 of environmental variation (CVe) reflected the precision of the phenotyping measurement

222 performed in this study, and the confidence of the analyses agreed with those of other popcorn 223 phenotyping studies (Guimarães et al., 2018; Miotto et al., 2016).

\section{$224 \quad$ 3.2. $\quad$ NIR spectral features}

225 The raw NIR spectra of all the popcorn kernels and the average SNV pre-processed 226 spectra did not show obvious differences between the two classes (Figure 1), even when the first

227 derivative of Savitzky-Golay was tested (data not shown). The NIR spectra exhibited two main 228 absorption bands at $1116 \mathrm{~nm}$ and $1300 \mathrm{~nm}$. The first is likely to be related to the second overtone 
229 due to the $\mathrm{C}_{\mathrm{ar}} \mathrm{H}$ group (Wust and Rudzik, 1996), attributed to the stretching vibration of the C-H 230 and $\mathrm{CH}_{3}$ groups associated with lignin, but a causal relationship could not be determined ( Alves

231 et al., 2010; Wust and Rudzik, 1996). The second absorption band could be attributed to the first

232 overtone due to the $\mathrm{C}-\mathrm{H}$ stretching vibration associated with hemicellulose (Schwanninger et al.,

233 2011). Both bands indicated the hard popcorn kernel endosperm (Quinn et al., 2005; van der

234 Sman and Bows, 2017). Five minor absorption bands were also observed and were related to the 235 presence of cellulose (1854 nm and $2026 \mathrm{~nm}$ ), O-H stretching vibration, and the second overtone 236 of the C-O group (Fujimoto et al., 2007, Fujimoto et al., 2008; Osborne and Fearn, 1998; Siesler 237 et al., 2002). The presence of lignin was again indicated by the absorption band at $2200 \mathrm{~nm}$, and 238 the $\mathrm{C}-\mathrm{H}$ and $\mathrm{C}=\mathrm{O}$ stretching vibrations (Workman and Weyer, 2007). Finally, the last absorption 239 band at $2404 \mathrm{~nm}$ could be related to the presence of carbohydrates (starch), indicated by the C-H 240 and C-C stretching vibrations (Schimleck and Evans, 2004).

\subsection{PE capacity}

The methodology described by Hoseney et al. (1983) was sufficient for determining the

244 PE capacity for all the populations of popcorn. The average PE was $31.5 \pm 6.7 \mathrm{~mL} . \mathrm{g}^{-1}$ with a 245 standard error (SD) of $6.7 \mathrm{~mL} \cdot \mathrm{g}^{-1}$. However, values as high as $48.9 \mathrm{~mL} \cdot \mathrm{g}^{-1}$ and as low as 11.5 $246 \mathrm{~mL} \cdot \mathrm{g}^{-1}$ were also observed.

\subsection{Chemometrics: PE prediction models}

SVR and iPLS regression methods were applied to compare the predictive performance of the best regression model using PLSR-1D (Table 2). An iPLS model was built using 1300 wavelengths selected by cross-validating using the $1^{\text {st }}$ derived spectra (Savitzky-Golay, window 
252 of 7 points, $2^{\text {nd }}$ order polynomial function). The calibration and validation performances were

253 estimated by the values of RMSEC and RMSEP, and the value of RMSEC was $6.03 \mathrm{~mL} \cdot \mathrm{g}^{-1}\left(\mathrm{R}_{\mathrm{c}}{ }^{2}\right.$

$254=0.27)$ and that of RMSEP was $5.64 \mathrm{~mL} \cdot \mathrm{g}^{-1}\left(\mathrm{R}_{\mathrm{p}}{ }^{2}=0.06\right)$. An SVR model was constructed using 255 a radial basis function kernel with 200 support vectors determined by cross-validation $(\operatorname{cost}=$ 256100 , epsilon $=1$, and gamma $=10$ ) with the $1^{\text {st }}$ derived spectra, where the value of RMSEC for 257 estimating the calibration performance was $7.05 \mathrm{~mL} \cdot \mathrm{g}^{-1}\left(\mathrm{R}_{\mathrm{c}}{ }^{2}=0.09\right)$, and the value of RMSEP for 258 estimating the validation performance was $5.53 \mathrm{~mL} \cdot \mathrm{g}^{-1}\left(\mathrm{R}_{\mathrm{p}}{ }^{2}=0.001\right)$.

\subsection{Chemometrics: PE classification models}

261 The PE capacity represents the quality of the popcorn and the acceptable PE values for 262 commercial purposes is approximately $30 \mathrm{~mL}^{-1}{ }^{-1}$ in Brazil (Pina Matta and Viana, 2001).

263 Therefore, the NIR spectra of all the popcorn kernels were separated into two classes (PE $\leq 30$ 264 and PE > $\left.30 \mathrm{~mL} \cdot \mathrm{g}^{-1}\right)$. Genotypes that have PE values > $30 \mathrm{~mL} \cdot \mathrm{g}^{-1}$ should be used in popcorn 265 breeding programs.

266 The first attempt to classify popcorn kernels was carried out using the raw NIR spectra 267 for developing the PCA-LDA and PCA-QDA models using four principal components (PCs) that 268 accounted for a cumulative variance of $99.88 \%$ (Figure 2). The GA-LDA and GA-QDA models 269 were developed by selecting the important variables. Specifically, the algorithm selected the 270 spectral variables at 1300, 1316, 1564, 1916, 1944, 2156, 2220, and $2238 \mathrm{~nm}$ for GA-LDA and 271 those at 1286, 1340, 1375, 1496, 1582, and $1672 \mathrm{~nm}$ for GA-QDA. However, it was not possible 272 to obtain a good discrimination between the popcorn classes on basis of the resulting scores 273 (Figure 2). 
275 QDA models were developed using 4 PCs accounting for 98.69\% of the cumulative variance

276 (Figure 3). The GA-LDA and GA-QDA models used different variables, namely the spectral 277 variables at 1280, 1211, 1230, and $2025 \mathrm{~nm}$ and the spectral variables at 1099, 1185, 1355, and

$2782022 \mathrm{~nm}$, respectively. A better discrimination was subsequently obtained between the PE 279 classes when compared to that achieved with the raw NIR spectra. For the non-pre-processed data, SIMCA (3 PCs for class 1 and 4 PCs for class 2, 99\%

281 explained variance, determined by cross-validation with venetian blinds using 10 data splits) and 282 PLS-DA (9 LVs determined by cross-validation with venetian blinds using 10 data splits, 100\% 283 explained variance) were performed for comparing the performance of the classification. The 284 SNV data were also analyzed by SIMCA (5 PCs for class 1 and 4 PCs for class 2, 99\% explained 285 variance, determined by cross-validation with venetian blinds using 10 data splits) and PLS-DA 286 (6 LVs determined by cross-validation with venetian blinds with 10 data splits, $99 \%$ explained 287 variance). For both the raw and pre-processed data, the performance of SIMCA and PLS-DA 288 were inferior to that of PCA-QDA.

289 The classification rates were determined for all the models (Table 3). The sensitivity 290 values of the SIMCA, PLS-DA, PCA-LDA, PCA-QDA, GA-LDA, and GA-QDA models were $29168.7 \%, 65.6 \%, 68.7 \%, 81.2 \%, 65.6 \%$, and 65.6\%, respectively, when SNV pre-processed NIR 292 spectra were used. Furthermore, the values of accuracy and specificity indicated that PE could be 293 better classified by the PCA-QDA model than by the other discriminant models (Table 3). 
The genetic variability observed in the $F_{2}$ and $F_{2: 3}$ populations should allow enhancement

297 of the genetic gains in popcorn quality through selection. The PE capacity is the best example of

298 such a trait in popcorn that can be enhanced through selection. The higher the precision in PE

299 phenotyping the greater is the chance of obtaining the best popcorn genotype. In addition, most

300 of the studies on popcorn genetic parameters have demonstrated that the genetic basis of PE is

301 controlled by additive allele effects (Cabral et al., 2015), which further facilitates the

302 enhancement of popcorn quality in breeding programs in terms of genetic gains.

303 The average PE value observed in this study reflected a modest but significant genetic

304 variability. The $F_{2}$ and $F_{2: 3}$ populations had the potential to produce genotypes with the desired

305 PE values of approximately $40 \mathrm{~mL}^{-1}{ }^{-1}$ (Pina Matta and Vianna, 2001), which is much higher than

$30630 \mathrm{~mL} \cdot \mathrm{g}^{-1}$ found in commercial Brazilian popcorn populations (Amaral Júnior, et al. 2013).

307 The focus of this study was to evaluate whether NIR spectroscopy could be used as a tool

308 for discriminating popcorn genotypes based on their PE capacity, and the results indicated that

309 NIR spectroscopy could indeed discriminate popcorn genotypes on the basis of this quality

310 parameter. The main NIR spectra absorption bands were associated with the presence of lignin

$311(1116 \mathrm{~nm}$ and $2200 \mathrm{~nm})$, hemicellulose $(1300 \mathrm{~nm})$, cellulose (1854 $\mathrm{nm}$ and $2026 \mathrm{~nm})$, and starch

312 (2404 nm), which possibly reflected the presence of a glassy (Quinn et al., 2005) and translucent

313 endosperm with densely packed starch granules that allow the kernels to expand explosively (van

314 der Sman and Bows, 2017). Maize kernels, including the hard, intermediate, and soft kernel

315 types contain both glassy and floury endosperm in different ratios (Williams et al., 2009). In the

316 hard kernel type, which is found in popcorn, the endosperm is primarily of a glassy nature. In

317 soft kernels, the endosperm is mostly floury (Sweley et al., 2013), and the NIR spectra obtained 
318 in this study was largely able to highlight the differences related to the presence of a hard kernel

319 in popcorn.

320 The accuracy of the PLS models for predicting the PE capacity of intact popcorn kernels

321 was reflected in the RMSEC $\left(6.08 \mathrm{~mL}^{-1}\right)$, which represented $19.3 \%$ of the average PE.

322 However, an $\mathrm{R}_{\mathrm{C}}{ }^{2}$ value of only 0.26 indicated a low proportion of explained variance in $\mathrm{PE}$ in the

323 calibration set. PLS models did not show good results due to the complexity of the data itself.

324 Even the testing results for variable selection by iPLS and non-linear regression by SVR were

325 inferior to that of PLS. This means that the spectral profile is affected by factors other than the

326 PE capacity of the kernel, and other experimental parameters such as moisture should be

327 measured for model correction. Baye et al. (2006) also reported low $\mathrm{R}^{2}$ values while predicting

328 protein (0.16) and starch (0.23) in single maize kernels using NIR spectra and PLS models that

329 were intended to be used by geneticists and breeders for screening large numbers of samples.

330 NIR spectroscopy can still be used a tool for non-destructively reducing the number of samples

331 to be tested, however, some tolerance for false positives and negatives is necessary. On the

332 whole, the PLSR model had a low value of RMSEC, but the low values of residual predictive

333 deviation (RPD) and $\mathrm{R}_{\mathrm{c}}{ }^{2}$ indicate that this model cannot be blindly used in popcorn breeding

334 programs for predicting PE values as inaccurate results are likely.

335 As the predictive model was not adequate, we tested the use of NIR spectroscopy for 336 classifying (discriminating) popcorn with different genetic compositions into different classes, 337 with the aim of rapid non-destructive phenotype selection, as this would probably be of greater

338 use to a popcorn breeding program. As the desirable value of PE for commercial purposes in 339 Brazil is approximately $30 \mathrm{~mL} \cdot \mathrm{g}^{-1}$ (Amaral Júnior et al., 2013), the genotypes that have PE 340 values above $30 \mathrm{~mL} \cdot \mathrm{g}^{-1}$ should be used in popcorn breeding programs for developing new 
341 cultivars. However, in order to discriminate popcorn kernels into the two PE $(\leq 30$ and $>30$

$342 \mathrm{~mL} \cdot \mathrm{g}^{-1}$ ) classes, no single NIR spectral feature could be employed for classification, making it

343 necessary to apply computational analysis such as SIMCA, PLS-DA, PCA-LDA, PCA-QDA, 344 GA-LDA, and GA-QDA.

345 The classification accuracy ranged from 62\% (SIMCA) to 76\% (GA-QDA) when the raw

346 NIR spectra was used. However, a clear separation between popcorn kernel classes without

347 overlap was not observed among the samples. This result might be related to the similarities

348 between these popcorn classes and kernels of other popcorn populations (Sobierajski, 2012). The

349 accuracy improved when the NIR spectra was pre-processed with SNV and the best result (78\%)

350 was obtained with PCA-QDA. Even though GA aided in selecting several important variables

351 and reduced the problems of collinearity, this technique was not superior to PCA-QDA.

352 Overall, the discrimination between the two popcorn classes based on PE was more 353 successful when PCA-QDA was applied, demonstrating that NIR spectroscopy together with 354 powerful chemometric approaches has the potential to detect and identify popcorn genotypes that 355 have PE values below and above the ideal target limit $\left(30 \mathrm{~mL} \cdot \mathrm{g}^{-1}\right)$ in a breeding program. 356 Recently, hyperspectral (NIR spectroscopy) imaging has been used to classify maize kernels on 357 the basis of hardness (Williams and Kucheryavskiy, 2016), highlighting the possibilities of using 358 NIR spectroscopy as a tool for discriminating popcorn kernels in breeding programs in the 359 future.

\section{Conclusion}

NIR spectroscopy can be used as a tool for discriminating intact popcorn kernels based 363 on their PE capacity. The quantitative PLS models developed herein should not be used in 
364 popcorn breeding programs as inaccurate PE prediction values are expected. Instead, the PCA365 QDA model can be applied for discriminating intact popcorn kernels with low PE $\left(\leq 30 \mathrm{~mL} \cdot \mathrm{g}^{-1}\right)$

366 from those with high PE (> $\left.30 \mathrm{~mL} \cdot \mathrm{g}^{-1}\right)$. Although NIR spectroscopy proved to be a promising

367 non-destructive method for assessing the PE capacity of intact popcorn kernels, it is necessary to

368 include more sources of variability and increase the sample size for improving the robustness of

369 the predictive and classificatory models.

\section{Acknowledgment}

372 This study was partially financed by the Coordenação de Aperfeiçoamento de Pessoal de 373 Nível Superior - Brasil (CAPES) - Finance Code 001.

\section{References}

377 Alves, A., Santos, A., Rozenberg, P., Paques, L.E., Charpentier, J.P., Schwanninger, M., 378 Rodrigues, J., 2010. A common near infrared-based partial least squares regression model for the 379 prediction of wood density of Pinus pinaster and Larix $\times$ eurolepis. Wood Science and 380 Technology 46, 157-175.

381 Amaral Júnior, A.T.D., Gonçalves, L.S.A., Júnior, F., de Paiva, S., Candido, L.S., Vittorazzi, C., 382 Scapim, C.A., 2013. UENF 14: a new popcorn cultivar. Crop Breeding and Applied 383 Biotechnology 13, 218-220.

384 Amodio, M.L., Ceglie, F., Chaudhry, M.M., Piazzolla, F., Colelli, G., 2017. Potential of NIR 385 spectroscopy for predicting internal quality and discriminating among strawberry fruits from 386 different production systems. Postharvest Biology and Technology 125, 112-121. 
Baia, T.C., Gama, R.A., de Lima, L.A.S., Lima, K.M.G., 2016. FTIR microspectroscopy coupled

388 with variable selection methods for the identification of flunitrazepam in necrophagous flies.

389 Analytical Methods 8, 968-972.

390 Baye, T.M., Pearson, T.C., Settles, A.M., 2006. Development of a calibration to predict maize

391 seed composition using single kernel near infrared spectroscopy. Journal of Cereal Science 43, $392 \quad 236-243$.

393 Brito, A.L.B., Brito, L.R., Honorato, F.A., Pontes, M.J.C., Pontes, L.F.B.L., 2013. Classification 394 of cereal bars using near infrared spectroscopy and linear discriminant analysis. Food Research 395 International 51, 924-928.

396 Bro, R., Smilde, A.K., 2014. Principal component analysis. Analytical Methods 6, 2812-2831.

397 Carvalho, L.C., Morais, C.L.M., Lima, K.M.G., Cunha Júnior, L.C., Nascimento, P.A.M., Faria, 398 J.B., Teixeira, G.H.A., 2016. Determination of the geographical origin and ethanol content of 399 Brazilian sugarcane spirit using near-infrared spectroscopy coupled with discriminant analysis. 400 Analytical Methods 8, 5658-5666.

401 Carvalho, L.C., Morais, C.L.M., Lima, K.M.G., Leite, G.W., Oliveira, G.S., Casagrande, I.P., 402 Teixeira, G.H.A., 2018. Using intact nuts and near infrared spectroscopy to classify macadamia 403 cultivars. Food analytical methods, 11, 1857-1866.

404 Costa, F.S., Silva, P.P., Morais, C.L.M., Theodoro, R.C., Arantes, T.D., Lima, K.M.G., 2017. 405 Comparison of multivariate classification algorithms using EEM fluorescence data to distinguish 406 Cryptococcus neoformans and Cryptococcus gattii pathogenic fungi. Analytical Methods 9, $407 \quad 3968-3976$.

408 Dixon, S.J., Brereton, R.G., 2009. Comparison of performance of five common classifiers 409 represented as boundary methods: Euclidean distance to centroids, linear discriminant analysis, 
410 quadratic discriminant analysis, learning vector quantization and support vector machines, as

411 dependent on data structure. Chemometrics and Intelligent Laboratory Systems 95, 1-17.

412 Fujimoto, T., Kurata, Y., Matsumoto, K., Tsuchikawa, S., 2008. Application of near infrared

413 spectroscopy for estimating wood mechanical properties of small clear and full length lumber

414 specimens. Journal of Near Infrared Spectroscopy 16, 529-537.

415 Fujimoto, T., Yamamoto, H., Tsuchikawa, S., 2007. Estimation of wood stiffness and strength

416 properties of hybrid larch by near-infrared spectroscopy. Applied Spectroscopy 61, 882-888.

417 Galvão, J.C.C., Sawazaki, E., Miranda, G.V., 2000. Comportamento de híbridos de milho-pipoca

418 em Coimbra, Minas Gerais, Brasil. Ceres 47, 201-2018.

419 Guimarães, A.G., Amaral Júnior, A.T., Lima, V.J.D., Leite, J.T., Scapim, C.A., Vivas, M., 2018.

420 Genetic gains and selection advances of the UENF-14 popcorn population. Revista Caatinga 31, $421 \quad 271-278$.

422 Hoseney, R.C., Zeleznak, K., Abdelrahman, A., 1983. Mechanism of popcorn popping. Journal 423 of Cereal Science 1, 43-52.

424 Kennard, R.W., Stone, L.A., 1969. Computer aided design of experiments. Technometrics 11, $425 \quad 137-148$.

426 McCall, J., 2005. Genetic algorithms for modelling and optimisation. Journal of Computational 427 and Applied Mathematics 184, 205-222.

428 Meng, Q., Murray, S.C., Mahan, A., Collison, A., Yang, L., Awika, J., 2015. Rapid estimation of 429 phenolic content in colored Maize by near-infrared reflectance spectroscopy and its use in 430 breeding. Crop Science, 55(5), 2234-2243. 
431 Miotto, A.A., Pinto, R.J.B., Scapim, C.A., Matias Junior, J.L., Coan, M.M.D., Silva, H.A.D.,

432 2016. Comparison of three tester parents in evaluating popcorn families derived from IAC-125.

433 Revista Ciência Agronômica 47, 564-571.

434 Nicolai, B.M., Beullens, K., Bobelyn, E., Peirs, A., Saeys, W., Theron, K.I., Lammertyna, J., 435 2007. Nondestructive measurement of fruit and vegetable quality by means of NIR spectroscopy: 436 A review. Postharvest Biology and Technology 46, 99-118.

437 Oliveira, G.H.F.D., Amaral, C.B.D., Revolti, L.T.M., Buzinaro, R., Moro, G.V., 2019. Genetic 438 variability in popcorn synthetic population. Acta Scientiarum 41, e39497.

439 Osborne, B.G., Fearn, T., 1998. Near infrared spectroscopy in food analysis. Longman Scientific 440 \& Technical, Harlow, Essex.

441 Pasquini, C., 2003. Near infrared spectroscopy: fundamentals, practical aspects and analytical 442 applications. Journal of the Brazilian Chemistry Society 14, 198-219.

443 Pina Matta, F., Viana, J.M.S., 2011. Testes de capacidade de expansão em programas de 444 melhoramento de milho-pipoca. Scientia Agricola 58, 847-851.

445 Quinn, P.V., Hong, D.C., Both, J.A., 2005. Increasing the size of a piece of popcorn. Physica A: 446 Statistical Mechanics and its Applications 353, 637-648.

447 Sabin, J.G., Ferrão, M.F., Furtado, J.C., 2004. Análise multivariada aplicada na identificação de 448 fármacos antidepressivos.Parte II: Análise por componentes principais (PCA) e o método de 449 classificação SIMCA. Revista Brasileira de Ciências Farmacêuticas 40, 387-396.

450 SAS., 2002. SAS User's guide: statistics, eighth ed. SAS Institute Inc. Cary.

451 Sawazaki, E., 2011. Nova geração de híbrido de milho para pipoca. Disponível em: 452 https://www.agrolink.com.br/noticias/nova-geracao-de-hibrido-de-milho-para-

453 pipoca_131978.html. Accessed 14 February 2019. 
454 Schimleck, L.R., Evans, R., 2004. Estimation of Pinus radiata D. Don tracheid morphological 455 characteristics by near infrared spectroscopy. Holzforschung 5, 66-73.

456 Schwanninger, M., Rodrigues, J.C., Fackler, K., 2011. A review of band assignments in near 457 infrared spectra of wood and wood components. Journal of Near Infrared Spectroscopy 19, 287458308.

459 Siesler, H.W., Ozaki, Y., Kawata, S., Heise, H.M., 2002. Near-infrared spectroscopy. Principles, 460 instruments, applications, first Ed. Wiley-VCH Verlag GmbH, Weinheim.

461 Cabral, P.D.S., Teixeira do Amaral, A., Pio Viana, A., Duarte Vieira, H., Jesus Freitas, I.L., 462 Vittorazzi, C., Vivas, M., 2015. Combining ability between tropical and temperate popcorn lines 463 for seed quality and agronomic traits. Australian Journal of Crop Science 9, 256.

464 Sinelli, N., Cerretani, L., Di Egidio, V., Bendini, A., Casiraghi, E., 2010. Application of near 465 (NIR) infrared and mid (MIR) infrared spectroscopy as a rapid tool to classify extra virgin olive 466 oil on the basis of fruity attribute intensity. Food Research International 43, 369-375.

467 Sobierajski, G.R., 2012. Desenvolvimento e uso de marcadores SSR e DArT para estudos de 468 diversidade genética em macadâmia (Macadamia integrifolia). PhD Thesis. Universidade São 469 Paulo, Piracicaba.

470 Sweley, J. C., Rose, D. J., \& Jackson, D. S. (2013). Quality traits and popping performance 471 considerations for popcorn (Zea mays Everta). Food reviews international 29, 157-177.

472 van der Sman, R.G.M., Bows, J.R., 2017. Critical factors in microwave expansion of starchy 473 snacks. Journal of Food Engineering 211, 69-84.

474 Williams, P., Geladi, P., Fox, G., Manley, M., 2009. Maize kernel hardness classification by near 475 infrared (NIR) hyperspectral imaging and multivariate data analysis. Analytica Chimica Acta $476 \quad 653,121-130$. 
477 Williams, P.J., Kucheryavskiy, S., 2016. Classification of maize kernels using NIR hyperspectral 478 imaging. Food Chemistry 209, 131-138.

479 Wong, K.H., Razmovski-Naumovski, V., Li, K.M., Li, G.Q., Chan, K., 2013. Differentiation of 480 Pueraria lobata and Pueraria thomsonii using partial least square discriminant analysis (PLS481 DA). Journal of Pharmaceutical and Biomedical Analysis 84, 5-13.

482 Workman, J., Weyer, L., 2007. Practical guide to interpretive near-infrared spectroscopy, first 483 ed. CRC Press, Boca Raton.

484 Wust, E., Rudzik, L., 1996. NIR-Spektroskopische analytik. In: Gunzler, A.M.B.H., Borsdorf, 485 R., Danzer, K., Fresenius, W., Galensa, R., Huber, W., Luderwald, I., Schwedt, G., Tolg, G., 486 Wisser, H. (Eds.), Infrarotspektroskopie. Highlight aus dem Analytiker-Taschenbuch. Springer, 487 Berlin, pp. 217-232.

488 Zinsly, J.R., Machado, J.A., 1987. Milho-pipoca. In: Paterniani, E., Viegas, G.P. (Eds.). 489 Melhoramento e produção de milho. Fundação Cargill, Piracicaba, pp.411-450. 


\section{Tables}

495

496 Table 1. Deviance analysis by the likelihood ratio test (LRT) among $62 \mathrm{~F}_{2}$ populations evaluated

497 for popping expansion $\left(\mathrm{PE}, \mathrm{mL} \cdot \mathrm{g}^{-1}\right)$.

\begin{tabular}{l} 
SV \\
\cline { 3 - 3 }
\end{tabular}


504 Table 2. Partial least squares regression (PLSR) for popcorn kernel popping expansion (PE, $\left.505 \mathrm{~mL} \cdot \mathrm{g}^{-1}\right)$.

PLSR

\begin{tabular}{lcccccc}
\hline & LV & $\mathrm{R}_{\mathrm{c}} 2$ & RMSEC & RMSECV & $\mathrm{R}_{\mathrm{p}} 2$ & RMSEP \\
\cline { 2 - 7 } PLSR-nil & 3 & 0.18 & 6.37 & 6.51 & 0.05 & 5.56 \\
SNV & 4 & 0.19 & 6.35 & 6.62 & 0.08 & 5.49 \\
PLSR-1D & 3 & 0.26 & 6.08 & 6.50 & 0.10 & 5.38 \\
PLSR-SVN+1D & 2 & 0.21 & 6.29 & 6.60 & 0.06 & 5.54
\end{tabular}

$506 \mathrm{LV}=$ latent variable, $\mathrm{RMSEC}=$ root mean square error of calibration, $\mathrm{RMSECV}=$ root mean

507 square error of cross-validation; RMSEP = root mean square error of prediction, nil $=$ raw NIR

508 spectra, $\mathrm{SNV}=$ standard normal variate, $1 \mathrm{D}=1^{\text {st }}$ derivative Savitzky-Golay (window of 7 points, $5092^{\text {nd }}$ order polynomial function). 
512 Table 3. Classification of popcorn kernels based on popping expansion (PE, mL.g ${ }^{-1}$ ) and NIR

513 spectroscopy using SIMCA, PLS-DA, PCA-LDA, PCA-QDA, GA-LDA, and GA-QDA.

\begin{tabular}{|c|c|c|c|c|c|c|c|}
\hline \multicolumn{8}{|l|}{ SIMCA } \\
\hline \multirow{2}{*}{ Pre-processing } & \multirow[b]{2}{*}{ Class } & \multicolumn{3}{|c|}{ Correct Classification (\%) } & \multicolumn{3}{|c|}{ Figure of Merit $(\%)$} \\
\hline & & Training & Validation & Test & Accuracy & Sensitivity & Specificity \\
\hline \multirow[t]{2}{*}{ None } & $>30$ & 78.3 & 61.1 & 66.7 & \multirow{2}{*}{62.0} & \multirow{2}{*}{59.4} & \multirow{2}{*}{66.7} \\
\hline & $<30$ & 64.9 & 65.6 & 59.4 & & & \\
\hline \multirow[t]{2}{*}{ SNV } & $>30$ & 74.7 & 55.6 & 61.1 & \multirow{2}{*}{66.0} & \multirow{2}{*}{68.7} & \multirow{2}{*}{61.1} \\
\hline & $<30$ & 66.2 & 71.9 & 68.7 & & & \\
\hline \multicolumn{8}{|l|}{ PLS-DA } \\
\hline \multirow[t]{2}{*}{ None } & $>30$ & 73.5 & 55.6 & 72.2 & \multirow{2}{*}{74.0} & \multirow{2}{*}{75.0} & \multirow{2}{*}{72.2} \\
\hline & $<30$ & 77.7 & 84.4 & 75.0 & & & \\
\hline \multirow[t]{2}{*}{ SNV } & $>30$ & 63.9 & 61.1 & 66.7 & \multirow{2}{*}{66.0} & \multirow{2}{*}{65.6} & \multirow{2}{*}{66.7} \\
\hline & $<30$ & 68.9 & 78.1 & 65.6 & & & \\
\hline \multicolumn{8}{|l|}{ PCA-LDA } \\
\hline \multirow{2}{*}{ None } & $>30$ & 57.8 & 44.4 & 66.7 & \multirow{2}{*}{70.0} & \multirow{2}{*}{71.9} & \multirow{2}{*}{66.7} \\
\hline & $<30$ & 54.7 & 43.7 & 71.9 & & & \\
\hline \multirow{2}{*}{ SNV } & $>30$ & 63.9 & 61.1 & 66.7 & \multirow{2}{*}{68.0} & & \\
\hline & $<30$ & 62.2 & 78.1 & 68.7 & & 08.1 & 00.1 \\
\hline PCA-QDA & & & & & & & \\
\hline None & $>30$ & 55.4 & 44.4 & 71.9 & 700 & 841 & 141 \\
\hline None & $<30$ & 67.6 & 59.4 & 84.4 & /U.U & 84.4 & 44.4 \\
\hline SNV & $>30$ & 61.4 & 55.6 & 72.2 & 780 & 812 & 722 \\
\hline Siv & $<30$ & 71.6 & 75.0 & 81.2 & 10.0 & 01.2 & 12.2 \\
\hline GA-LDA & & & & & & & \\
\hline None & $>30$ & 80.7 & 66.7 & 55.6 & 740 & 844 & 556 \\
\hline None & $<30$ & 77.0 & 84.4 & 84.4 & 14.0 & 04.4 & 55.0 \\
\hline SNV & $>30$ & 65.1 & 66.7 & 77.8 & 700 & 656 & 778 \\
\hline STV & $<30$ & 60.8 & 78.1 & 65.6 & 10.0 & 05.0 & 11.0 \\
\hline GA-QDA & & & & & & & \\
\hline & $>30$ & 80.7 & 77.8 & 66.7 & & & \\
\hline None & $<30$ & 66.9 & 78.1 & 81.2 & 16.0 & 81.2 & 66.1 \\
\hline SNV & $>30$ & 72.2 & 72.2 & 72.2 & 680 & 656 & 2 72 \\
\hline $\mathrm{ST}$ & $<30$ & 78.1 & 78.1 & 65.6 & 00.0 & 00.0 & 12.2 \\
\hline
\end{tabular}

Soft independent modeling of class analogy (SIMCA), parcial least square regression with discriminant analysis (PLS-DA), principal component analysis linear with discriminant analysis (PCA-LDA), principal component analysis with quadratic discriminant analysis (PCA-QDA), genetic algorithm with linear discriminant analysis (GA-LDA), and genetic algorithm with 518 quadratic discriminant analysis (GA-QDA). SNV = standard normal variate 


\section{Figures}

524
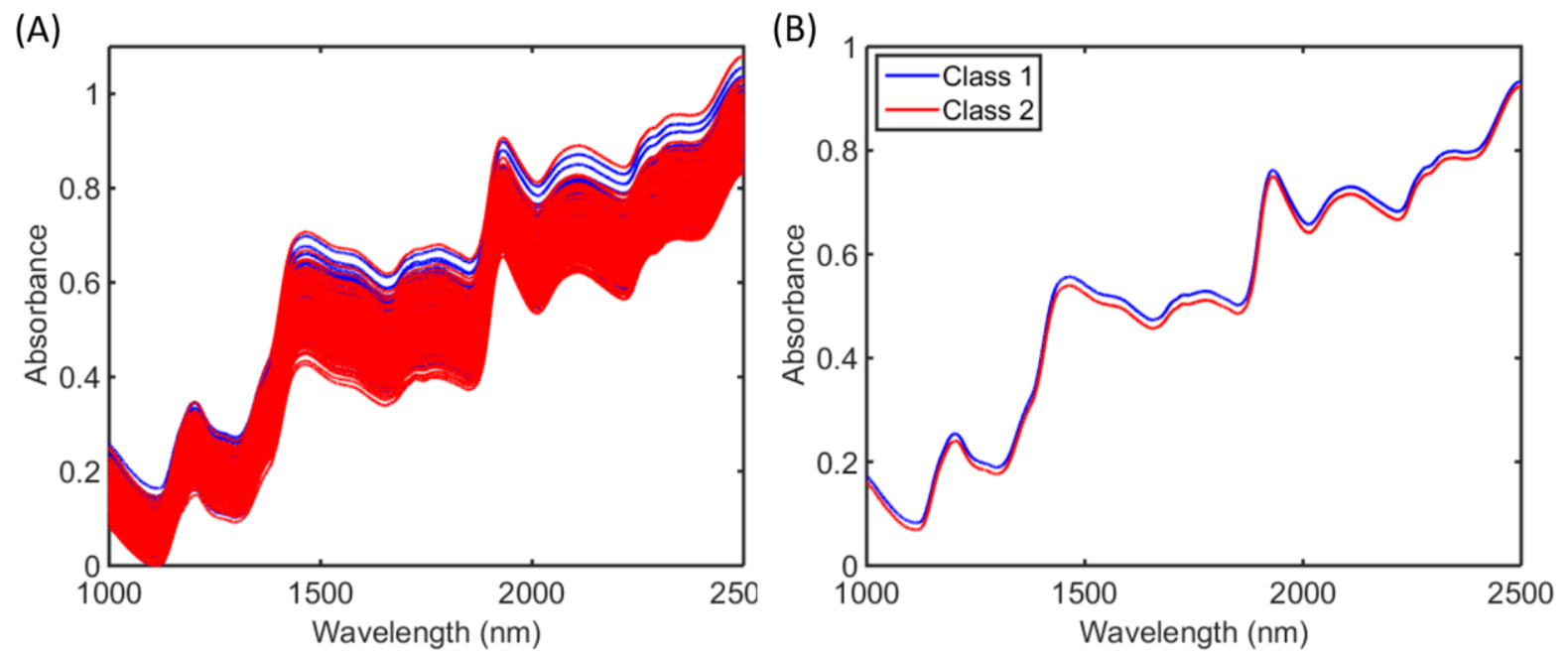

526 Figure 1. Near infrared spectra $\left(-\log _{10} \mathrm{R}\right)$ of all popcorn kernel samples (A), average spectra for

527 each original class of popcorn sample (B). Class $1\left(\mathrm{PE} \leq 30 \mathrm{~mL} \cdot \mathrm{g}^{-1}\right)$ and Class $2\left(\mathrm{PE}>30 \mathrm{~mL} \cdot \mathrm{g}^{-}\right.$ $\left.528{ }^{1}\right)$. 

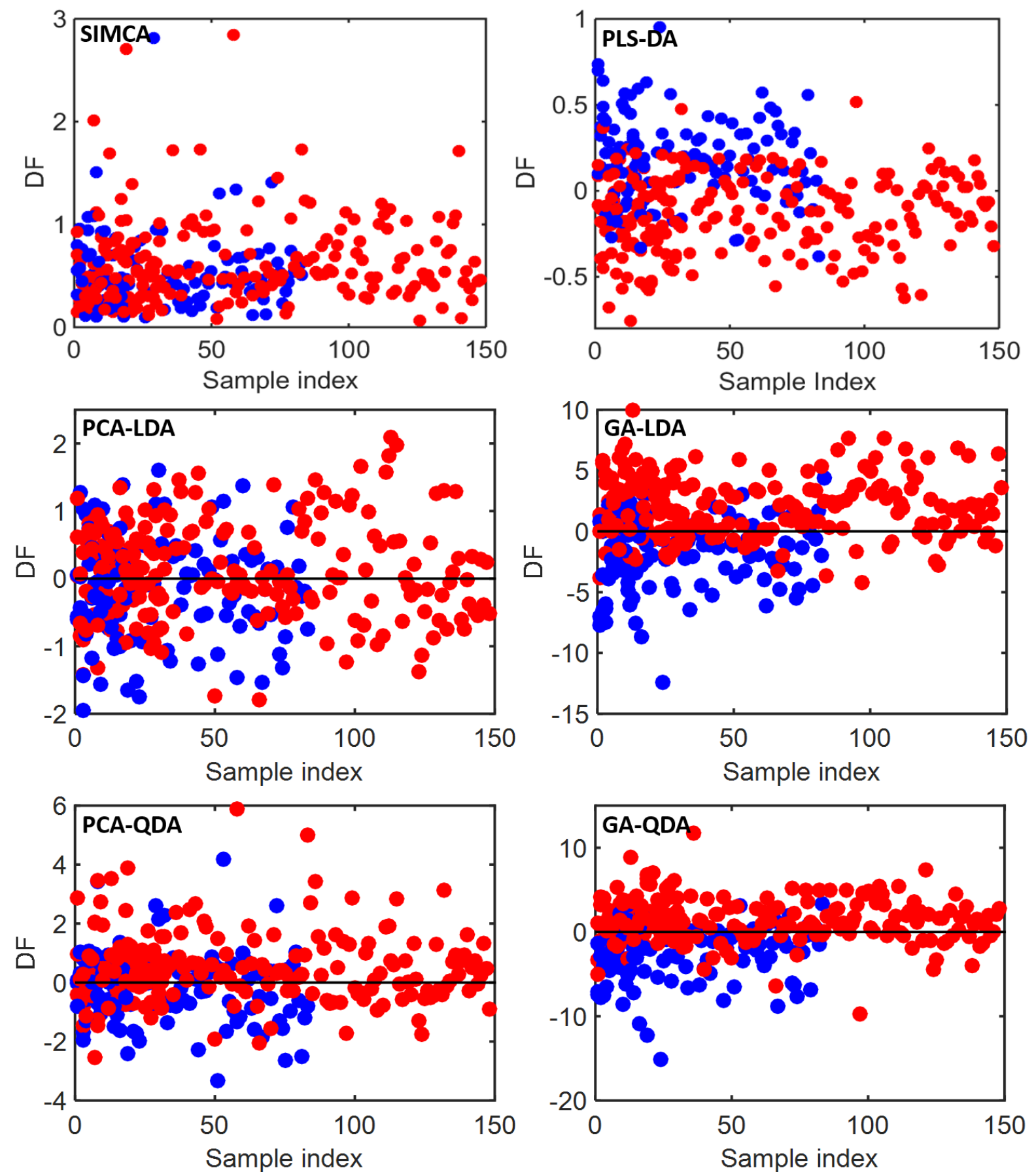

531 Figure 2. Discriminant function (DF) versus samples calculated by using SIMCA, PLS-DA,

532 PCA-LDA, PCA-QDA, GA-LDA, and GA-QDA models from two classes of popping expansion

533 (PE). Red dots, class $1\left(\mathrm{PE} \leq 30 \mathrm{~mL} \cdot \mathrm{g}^{-1}\right)$ and blue dots, class $2\left(\mathrm{PE}>30 \mathrm{~mL} \cdot \mathrm{g}^{-1}\right)$ without NIR

534 spectra pre-processing. 

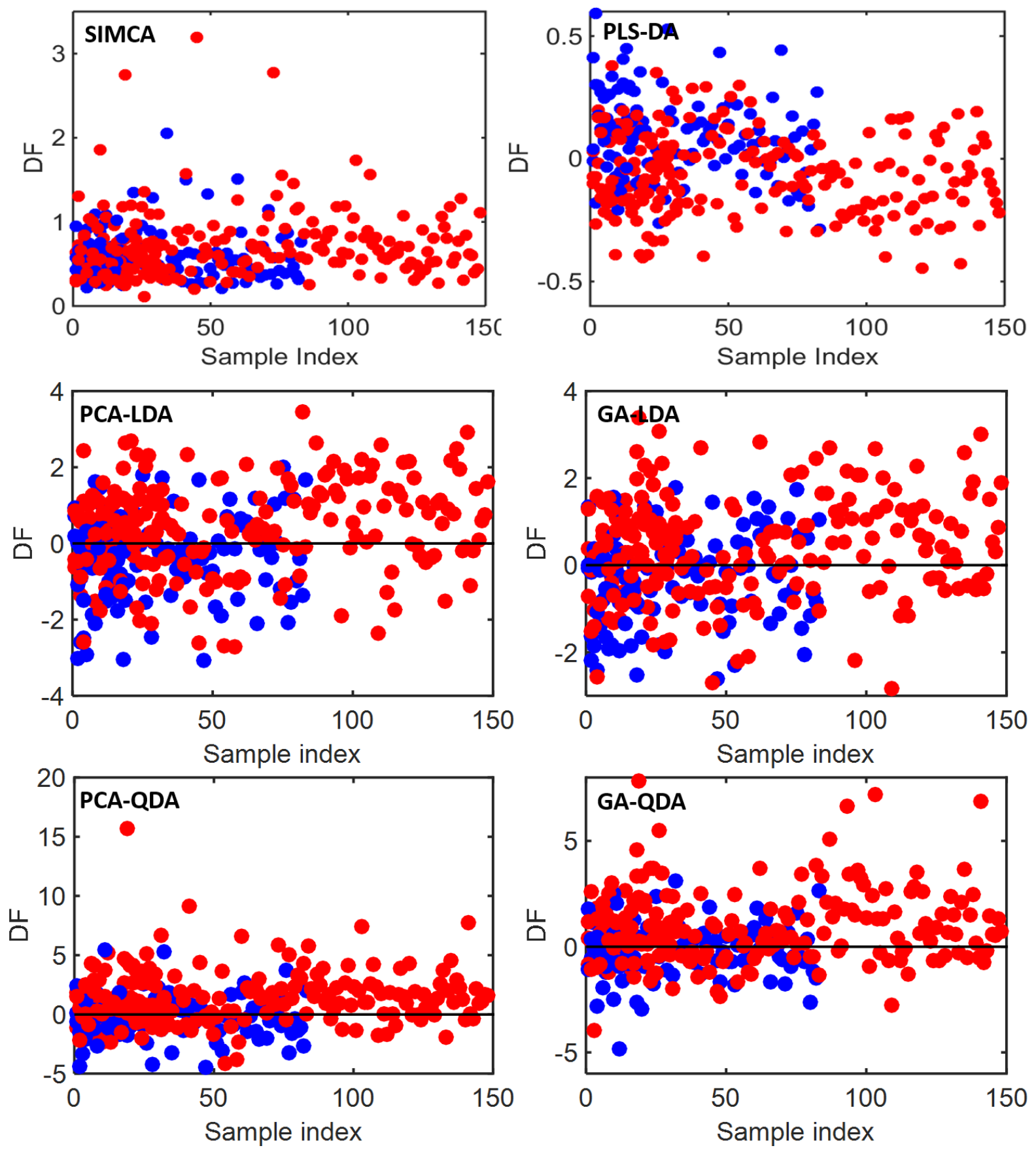

538 Figure 3. Discriminant function (DF) versus samples calculated by using SIMCA, PLS-DA,

539 PCA-LDA, PCA-QDA, GA-LDA, and GA-QDA models from two classes of popping expansion

540 (PE). Red dots, class $1\left(\mathrm{PE} \leq 30 \mathrm{~mL} \cdot \mathrm{g}^{-1}\right)$ and blue dots, class $2\left(\mathrm{PE}>30 \mathrm{~mL}^{-1} \mathrm{~g}^{-1}\right)$ with NIR

541 spectra pre-processed with SNV. 